This item was submitted to Loughborough's Research Repository by the author.

Items in Figshare are protected by copyright, with all rights reserved, unless otherwise indicated.

\title{
Chemically bonded phosphate ceramics reinforced with carbon nanotubes
}

PLEASE CITE THE PUBLISHED VERSION

http://dx.doi.org/10.1002/9781118807828.ch10

\section{PUBLISHER}

(c) The American Ceramic Society. Published by John Wiley \& Sons.

\section{VERSION}

AM (Accepted Manuscript)

\section{PUBLISHER STATEMENT}

This work is made available according to the conditions of the Creative Commons Attribution-NonCommercialNoDerivatives 4.0 International (CC BY-NC-ND 4.0) licence. Full details of this licence are available at: https://creativecommons.org/licenses/by-nc-nd/4.0/

\section{LICENCE}

CC BY-NC-ND 4.0

\section{REPOSITORY RECORD}

Wade, James, Jingjing Liu, and Houzheng Wu. 2015. "Chemically Bonded Phosphate Ceramics Reinforced with Carbon Nanotubes”. figshare. https://hdl.handle.net/2134/18976. 


\section{CHEMICALLY BONDED PHOSPHATE CERAMICS REINFORCED WITH CARBON NANOTUBES}

James Wade, Jingjing Liu \& Houzheng Wu

Department of Materials, Loughborough University, Leicestershire, LE11 3TU, UK

\section{ABSTRACT}

We report herein, a scalable method for the preparation of alumina $\left(\mathrm{Al}_{2} \mathrm{O}_{3}\right)$-phosphate ceramics reinforced with carbon nanotubes (CNTs). All composites were manufactured by direct on-site growth of CNTs on ceramic particles via catalytic chemical vapour deposition. Introduction of catalyst metals to the substrate was achieved through two simple approaches, drip-coating and vacuum filtration, both of which have been reviewed. Transmission electron microscopy was utilised to investigate the interface between the $\mathrm{Al}_{2} \mathrm{O}_{3}$ surface and the in-situ CNTs. Resultant ceramics were produced by impregnating phosphoric acid into the $\mathrm{Al}_{2} \mathrm{O}_{3}+\mathrm{CNT}$ nanocomposite powder followed by die-pressing. In order to maintain the integrity of the CNTs, dehydration/curing was performed at $130-150^{\circ} \mathrm{C}$. Scanning electron microscopy was elected to comparatively characterise the microstructure of this type of ceramic nanocomposite against its monolithic equivalent. Possible mechanisms by which specific features have formed are discussed.

\section{INTRODUCTION}

Since the widespread circulation of a Sumio Iijima's 1991 paper titled 'helical microtubules of graphitic carbon', CNTs have accrued world-wide status as a material of the future and a range of potential applications have been suggested for the aeronautical, automotive and construction industries ${ }^{1,2,3}$. These high expectations have mainly stemmed from the nanostructures unique combination of properties. Table 1 lists the commonly cited mechanical, electrical and thermal capabilities of CNTs.

Table 1: The mechanical, electrical and thermal properties of both SWCNTs and MWCNTs.

\begin{tabular}{|l|l|l|}
\hline \multirow{2}{*}{ Mechanical } & Young's Modulus & $\sim 1 \mathrm{TPa}^{4,5}$ \\
\cline { 2 - 3 } Electrical & Tensile Strength Electrical & $63 \mathrm{GPa}^{6}$ \\
\hline \multirow{3}{*}{ Thermal } & $\begin{array}{l}\text { Saximum } \\
\text { Conductivity } \\
\text { MWCNTs }=300 \mathrm{~K} \sim 106 \mathrm{~S} / \mathrm{m}\end{array} 105 \mathrm{~S} / \mathrm{m}^{7,8}$ \\
& $\begin{array}{l}\text { Maximum Thermal } \\
\text { Conductivity }\end{array}$ & $\begin{array}{l}\text { SWCNTs }=6600 \mathrm{~W} / \mathrm{Mk} \\
\text { MWCNTs }=>3000 \mathrm{~W} / \mathrm{mK}^{9,10}\end{array}$ \\
\cline { 2 - 3 } & Thermal Stability (in Argon) & $2000-2400^{\circ} \mathrm{C}^{11,12}$ \\
\hline
\end{tabular}

Unsurprisingly, present studies involving the use of CNTs as reinforcements have been overshadowed by the potential electrical applications. Hence, the majority of recent research is fixated on developing a consistent and scalable means of CNT production for use within the electronics industry. However, depending on the method, problems such as chirality ${ }^{13,14}$, irremovable functional groups and defects ${ }^{15}$, and the scattering of electrons by optical phonons ${ }^{16,17}$ are regularly encountered. This ultimately leads to undesirable electrical properties with no foreseeable solution in sight.

As reinforcements, the aforementioned issues are far less important and have minimal, if any influence over the mechanical properties. As such, carbon nanotubes can be synthesised using a plethora of sublimation and chemical based techniques. These methods include the electric arc discharge process, laser ablation, production by electrolysis, heat treatment of a polymer or low temperature solid pyrolysis ${ }^{18}$. 
Instead difficulties are faced during the preparation of ceramic matrix nanocomposites and present themselves in the form of nanotube agglomeration, alignment and inhomogeneous dispersion throughout the bulk matrix ${ }^{19,20,21}$.

Fortunately, a novel solution has since been developed by Flahaut and co-workers that modifies the chemical vapour deposition (CVD) technique to form a process called in-situ catalytic CVD (CCVD) $)^{22}$. This involves the "growth" of rooted CNTs directly on the ceramic particle surface, thereby avoiding the previously mentioned issues by bypassing any sort of free-mixing of CNTs with ceramic powders. Current complications are alternatively found at the following stages:

- Densification - CNTs located at the interface between ceramic particles act as a "cushion zone", resisting compression and creating a final ceramic of relatively low density $(<90 \%)^{23,24}$.

- Sintering - CNTs are unable to tolerate and tend to degrade at the high temperatures traditionally applied during conventional ceramic sintering ${ }^{25}$.

As a result, on-going research efforts are concentrated on achieving fully dense CNT reinforced ceramic matrix nanocomposites whilst simultaneously maintaining the integrity of the CNTs dispersed within the matrix.

In this paper, we document the results accumulated to date on the growth of CNTs on $\mathrm{Al}_{2} \mathrm{O}_{3}$ particles with cobalt $(\mathrm{Co})$ acting as a catalyst metal and methane gas $\left(\mathrm{CH}_{4}\right)$ as a hydrocarbon source. Additionally, we report on subsequent attempts to achieve low temperature densification of phosphoric acid impregnated CNT reinforced $\mathrm{Al}_{2} \mathrm{O}_{3}$ ceramics.

\section{EXPERIMENTAL METHODOLOGY}

\section{(a) Starting Materials}

Synthesis of CNTs was achieved via in-situ CCVD of cobalt metal nanoparticles scattered over a substrate of $99.7 \%$ chemically pure $\alpha-\mathrm{Al}_{2} \mathrm{O}_{3}$ powder (Sigma Aldrich, UK) with a mean particle size of $10 \mu \mathrm{m}$. The cobalt catalyst selected was formed through the reduction of cobalt (II) nitrate hexahydrate (Fisher Chemicals, UK). Distribution of the precursor over the $\mathrm{Al}_{2} \mathrm{O}_{3}$ surface was performed in solution ahead of the CCVD process. A cobalt nitrate salt $\left(\mathrm{Co}\left(\mathrm{NO}_{3}\right)_{2} \cdot 6 \mathrm{H}_{2} \mathrm{O}\right)$ of 98\% purity was mechanical stirred for 30 minutes in reagent grade acetone (Sigma Aldrich, UK) at various ratios depending on the desired concentration and quantity. Typically, a ratio $1.16 \mathrm{~g}: 40 \mathrm{ml}$ was used and equated to $0.1 \mathrm{~mol} / 1$. However, concentrations $0.05,0.3$ and $0.6 \mathrm{~mol} / 1$ were also formulated.

\section{(b) Catalyst Distribution}

In this study, the efficiency of two low-cost, highly scalable modes of catalyst distribution were investigated:

The first approach developed was drip-coating and involved the use of a pipette to deliver droplets of the precursor solution over a uniform layer of $\mathrm{Al}_{2} \mathrm{O}_{3}$ powder $(\sim 5 \mathrm{~g})$ until a Fisherbrand QL 100, qualitative, medium retention, 90mm diameter filter (Fisher Scientific, UK) beneath became fully-saturated. The powder was then placed in an oven at $60^{\circ} \mathrm{C}$ for 30 minutes to allow any residual acetone to evaporate. Once dried, the powder was milled and collected in a porcelain boat awaiting the CCVD process.

The second method was vacuum filtration. Here, an $\mathrm{Al}_{2} \mathrm{O}_{3}$ powder/catalyst precursor suspension was made by taking $20 \mathrm{ml}$ of the precursor solution and adding it to a beaker containing $20 \mathrm{~g}$ of $\mathrm{Al}_{2} \mathrm{O}_{3}$ powder. Subsequent mixing was achieved either solely by mechanical stirring or a combination of mechanical and ultrasonic agitation. In both cases, mechanical mixing comprised of manually churning the precursor solution until the $\mathrm{Al}_{2} \mathrm{O}_{3}$ powder sediment at the bottom of the 
beaker was in suspension. Any further ultrasonication was performed for 10 minutes in a UD150SH-6L 230W (Ultra-Piezo, Beijing, China) ultrasonic bath. This was followed by vacuum filtration with all suspensions being passed through the same Fisherbrand QL 100 filters. Drying of the powders after filtration was completed in an oven at $60^{\circ} \mathrm{C}$ for 30 minutes. The resultant dried block was then crushed back into a powder using a pestle and mortar. This process was repeated between 1 and 6 times using the same catalyst precursor concentration. As will be discussed in further detail later, varying the concentration and the number of filtrations can dramatically impact on the CNT growth after CCVD.

(c) In-situ Catalytic Chemical Vapour Deposition

Methane gas (BOC Special gases, UK) was chosen as a hydrocarbon source for the CCVD process whilst a special gas mix consisting of $\mathrm{N}_{2}+3 \% \mathrm{H}_{2}$ (BOC Special Gases, UK) had two purposes, to promote a reducing atmosphere in order to trigger the reduction of the catalyst precursor, and to improve the carbon absorption by the catalyst at the cracking temperature.

Both gases were feed into a $55 \%$ purity $\mathrm{Al}_{2} \mathrm{O}_{3}$ working tube (Lenton, UK) with a $25 \mathrm{~mm}$ diameter and a 700mm length. The tube was positioned in a Lenton LTF 12/38/250 temperature controlled, horizontal tube furnace and was sealed at both ends to prevent oxygen contamination during the CCVD process.

Once prepared, the tube furnace and gas flow was manually controlled in order to adhere to the following steps:

Table 2: The necessary steps for catalytic chemical vapour deposition.

\begin{tabular}{|l|l|l|}
\hline Steps & Programme details & $\begin{array}{l}\text { Control of the gases } \\
\text { [Litres per minute (LPM)] }\end{array}$ \\
\hline Ramp to $450^{\circ} \mathrm{C}$ & Heating rate $10^{\circ} \mathrm{C} / \mathrm{min}$ & SG on at 1 LPM \\
\hline Dwell at $450^{\circ} \mathrm{C}$ & 10 minutes & $\begin{array}{l}\text { SG increased to } \\
3 \mathrm{LPM}\end{array}$ \\
\hline $\begin{array}{l}\text { Ramp from } 450^{\circ} \mathrm{C} \mathrm{to} \\
\text { cracking temperatures }\end{array}$ & $\begin{array}{l}\text { Heating to } 650^{\circ} \mathrm{C}-1000^{\circ} \mathrm{C} \\
\text { at a rate of } 10^{\circ} \mathrm{C} / \mathrm{min}\end{array}$ & $\begin{array}{l}\text { Maintain SG at 3 LPM } \\
\text { Methane on at 2 LPM }\end{array}$ \\
\hline $\begin{array}{l}\text { Dwell at cracking } \\
\text { temperature }\end{array}$ & 60 minutes & $\begin{array}{l}\text { Maintain SG at 3 LPM } \\
\text { Methane on at 2 LPM }\end{array}$ \\
\hline $\begin{array}{l}\text { Cool from cracking } \\
\text { temperature to } 25^{\circ} \mathrm{C}\end{array}$ & Air cooled & $\begin{array}{l}\text { Reduce SG to 1 LPM } \\
\text { Methane gas off }\end{array}$ \\
\hline At $25^{\circ} \mathrm{C}$ & Power off & SG off at 200 $\mathrm{C}$ \\
\hline
\end{tabular}

*SG refers to the nitrogen $+3 \%$ hydrogen mix (BOC Special Gases, UK)

(d) Preparation of Chemically Bonded Phosphate Ceramics Reinforced with Carbon Nanotubes

Samples of $\mathrm{Al}_{2} \mathrm{O}_{3}$-phosphate reinforced with CNTs were fabricated by impregnating phosphoric acid $\left(\mathrm{H}_{3} \mathrm{PO}_{4}\right)$ into the post-CCVD $\mathrm{Al}_{2} \mathrm{O}_{3}+\mathrm{CNT}$ nanocomposite powders. Distilled water was used to dilute 99\% pure phosphoric acid crystals (Sigma-Aldrich, UK) into a 50wt\% concentrated acid solution. Approximately $1 \mathrm{ml}$ of this was then added to $0.3-0.7 \mathrm{~g}$ of $\mathrm{Al}_{2} \mathrm{O}_{3}+\mathrm{CNT}$ nanocomposite powder. Upon mixing, an immediate dissolution of the $\mathrm{Al}_{2} \mathrm{O}_{3}$ grits formed a gellike substance, expressed by the reaction below:

$$
\mathrm{Al}_{2} \mathrm{O}_{3}+6 \mathrm{H}_{3} \mathrm{PO}_{4} \rightarrow 2 \mathrm{Al}\left(\mathrm{H}_{2} \mathrm{PO}_{4}\right)_{3} \cdot 3 \mathrm{H}_{2} \mathrm{O} \quad \text { (dissolution of } \mathrm{Al}_{2} \mathrm{O}_{3} \text { ) }
$$

Displacement of the excess phosphoric acid and densification of the $\mathrm{Al}_{2} \mathrm{O}_{3}$ powder was accomplished by die-pressing the gel. In order to ensure the CNTs remained undamaged, a low 
pressure of $150 \mathrm{MPa}$ was used. The resultant pellets were subsequently sealed in petri dishes and heated in an oven at $130^{\circ} \mathrm{C}$. The reaction that ensues is as follows:

$$
\mathrm{Al}\left(\mathrm{H}_{2} \mathrm{PO}_{4}\right)_{3} \cdot 3 \mathrm{H}_{2} \mathrm{O} \rightarrow \mathrm{AlPO}_{4}+3 \mathrm{H}_{2} \mathrm{O}+2 \mathrm{H}_{3} \mathrm{PO}_{4} \quad \text { (dehydration) }
$$

By encapsulating the samples, a contained atmosphere was created which facilitated a slower water evaporation rate. This ultimately reduced the porosity within the final structure by prohibiting the formation of air bubbles during the dehydration process.

After 48 hours, the samples were unsealed and exposed to an increased temperature of $150^{\circ} \mathrm{C}$ for another 48 hours. This final curing reaction is given by:

$$
\mathrm{Al}_{2} \mathrm{O}_{3}+2 \mathrm{H}_{3} \mathrm{PO}_{4} \stackrel{\Delta\left(130 \sim 150^{\circ} \mathrm{C}\right)}{\longrightarrow} 2 \mathrm{AlPO}_{4}+3 \mathrm{H}_{2} \mathrm{O}
$$

The aforementioned process was also implemented to produce monolithic $\mathrm{Al}_{2} \mathrm{O}_{3}$-phosphate samples which acted as a control material from which the introduction of CNTs could be comparatively analysed.

(e) Microstructural Characterisation

For both the $\mathrm{Al}_{2} \mathrm{O}_{3}$ particles after CCVD and the $\mathrm{Al}_{2} \mathrm{O}_{3}$-phosphate ceramics, field emission gun scanning electron microscopy (FEGSEM) examinations were performed using a Carl Zeiss (Leo) 1530 VP. Prior to FEGSEM, samples were either spread or placed on a carbon pad and sputter-coated with a thin coating of gold-palladium to prevent charging. Visualising the CNTs was achieved by using the in-lens detector at the following optimised settings: electron voltage of 5.00 $\mathrm{kV}$ and a working distance $<5.0 \mathrm{~mm}$.

A FEI Philips TECNAI F20 with a scanning transmission electron microscope (STEM) and an Oxford Isis energy dispersive x-ray spectroscope (EDS) was used in high resolution TEM (HRTEM) lattice imaging mode to investigate the interfacial contact between catalyst particles and $\mathrm{Al}_{2} \mathrm{O}_{3}$ substrate surface. This was achieved using a magnification of $1000 \mathrm{k}$, an accelerating voltage of $200 \mathrm{kV}$ and a beam current of $40 \mu \mathrm{A}$.

\section{RESULTS AND DISCUSSION}

(a) Effectiveness of CNT growth via in situ CCVD

Fig. 1(a-b) shows FEGSEM images highlighting the dispersion of the cobalt nanoparticles over the $\mathrm{Al}_{2} \mathrm{O}_{3}$ grits after both modes of catalyst distribution.

By employing the drip-coating method, a mixture of large $(\sim 50-150 \mathrm{~nm})$, medium $(\sim 20$ $40 \mathrm{~nm})$ and small nanoparticles $(\sim 5-10 \mathrm{~nm})$ are heterogeneously spread across the $\mathrm{Al}_{2} \mathrm{O}_{3}$ surface. Some regions are intimately packed with clusters of catalyst particles, whilst large valleys in between remain clear.

Conversely, the vacuum filtration method demonstrates a more homogeneous distribution of uniform medium-sized nanoparticles $(\sim 20-40 \mathrm{~nm})$. Fig. 1(b) represents the $\mathrm{Al}_{2} \mathrm{O}_{3}$ powder after 3 filtrations of the cobalt nitrate solution at a concentration of $0.1 \mathrm{~mol} / 1$. Altering the number of filtrations or the concentration of the precursor solution directly influences the final population of cobalt catalyst nanoparticles as well as their proximity. However, this does not translate into additional CNTs after the CCVD process. 

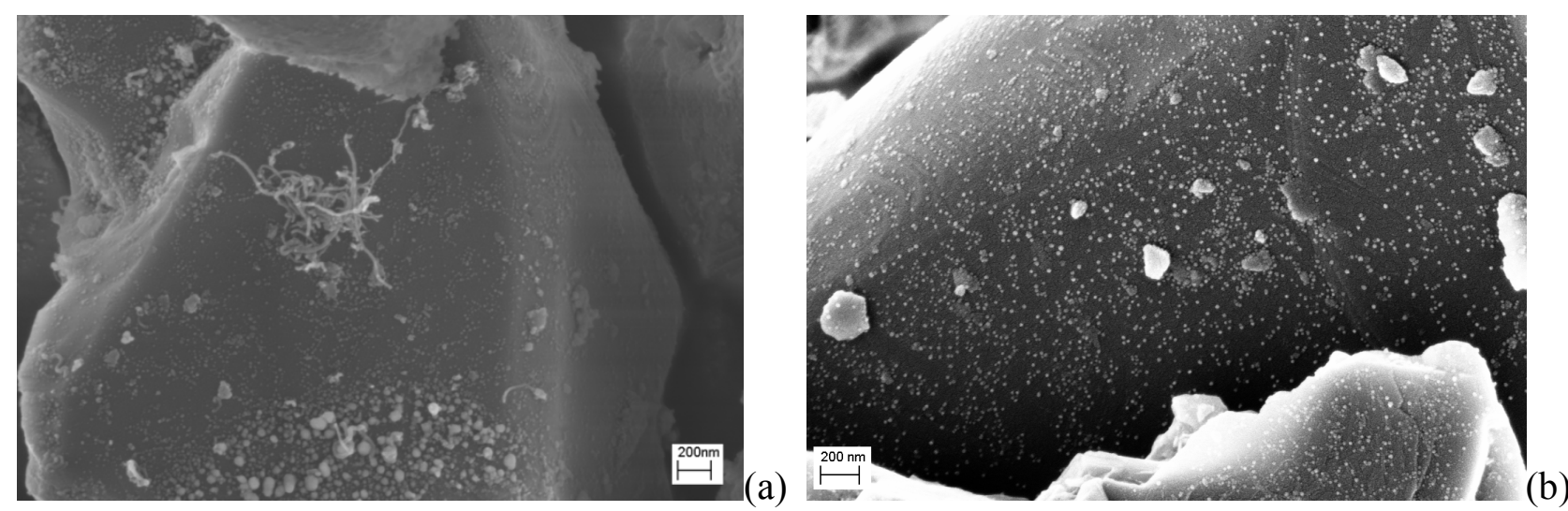

Figure 1: The catalyst distribution displayed across the surface of an $\mathrm{Al}_{2} \mathrm{O}_{3}$ powder particle after (a) drip-coating of precursor solution at a concentration of $0.3 \mathrm{~mol} / 1$ (b) $3 \times$ vacuum filtration of precursor solution at a concentration of $0.1 \mathrm{~mol} / 1$.

Fig. 2(a-b) are exemplary representations of CNT yields that are achievable with each respective method.

For drip-coating, a dense, thick "forest" of CNTs, $\sim 1-2 \mu \mathrm{m}$ in length and $\sim 20 \mathrm{~nm}$ in diameter, envelope the $\mathrm{Al}_{2} \mathrm{O}_{3}$ surface. Comparatively, vacuum filtration exhibits scattered growth of CNTs much shorter in length $(\sim 0.5-1 \mu \mathrm{m})$, but similar in diameter $(\sim 20-30 \mathrm{~nm})$. Whilst the measured diameters are consistent with MWCNTs, as reported in the literature $26,27,28,29$, the limited variance implies that for cobalt metal nanoparticles to experience CNT growth the total permissible deviation in size is extremely stringent.

Consequently, despite the superior CNT growth density displayed across one model particle, the dimensional assortment of the catalyst particles produced via drip-coating ultimately means that CNT synthesis over the entire sample is incongruent. It should also be noted that CNT growth from batch to batch was also highly unpredictable, often resulting in no CNTs at all. This observed inhomogeneity/inconsistency is not ideal for ceramic matrix nanocomposite manufacture as it generates unreinforced sites which act as localised regions of weakness.
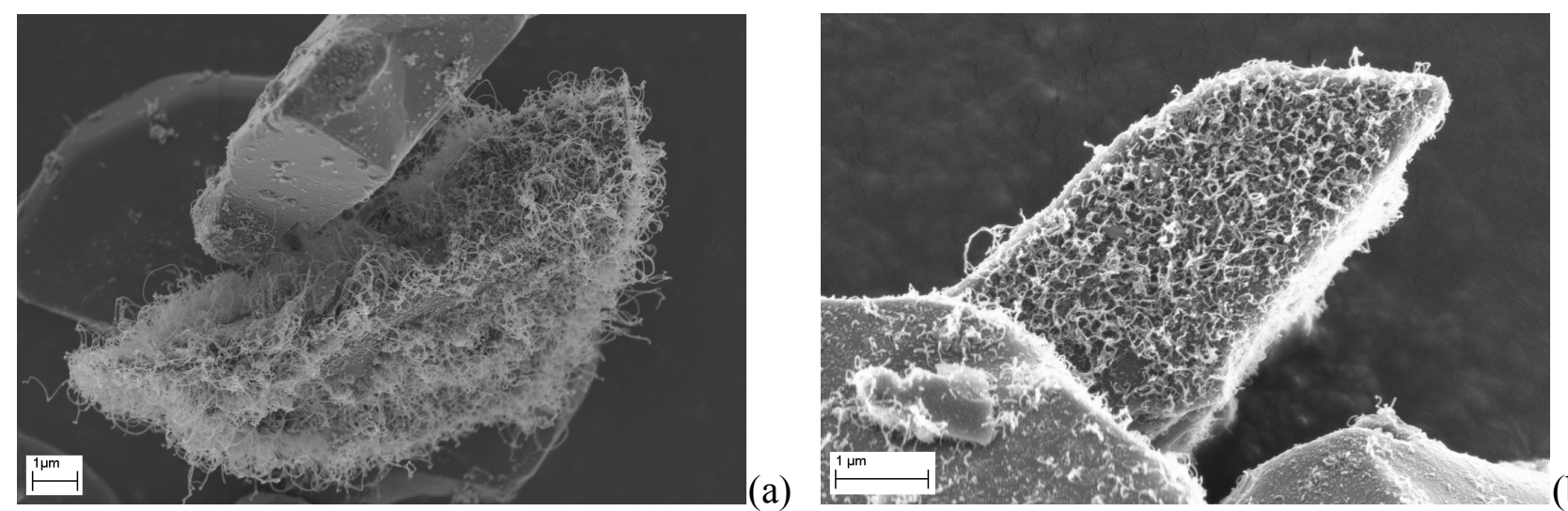

Figure 2: Examples of feasible growth densities on $\mathrm{Al}_{2} \mathrm{O}_{3}$ particles after $\mathrm{CCVD}$ at $650^{\circ} \mathrm{C}$ in an oxygen free atmosphere (a) drip-coating (b) vacuum filtration.

Fig. 3a illustrates this poor continuity by highlighting the extreme contrast in growth from particle to particle. As shown, a select few surfaces feature optimal CNT coverage whilst the majority of the surrounding $\mathrm{Al}_{2} \mathrm{O}_{3}$ grits are either saturated in cobalt catalyst metal or completely untouched. In both cases, the $\mathrm{Al}_{2} \mathrm{O}_{3}$ particles are virtually CNT-free. Instead, substantial quantities of graphitic flakes have formed. It is possible that large regions of closely situated cobalt catalyst found on oversaturated particles act as a film facilitating the graphitisation of amorphous carbon 
that accumulates at lower temperatures ${ }^{30}$. For vacuum filtration, this mechanism would explain why continually increasing the number of filtrations eventually inhibits CNT growth as the spacing between the catalyst nanoparticles gradually reduces. Similarly, increasing the concentration of the precursor solution leads to limited CNT synthesis. Nevertheless, this is attributed to the agglomeration of cobalt catalyst particles to a size that exceeds the $20 \mathrm{~nm}$ required for CNTs to form.

By adopting a reasonable number of filtrations and maintaining a relatively low cobalt nitrate/acetone concentration $(\leq 0.1 \mathrm{~mol} / \mathrm{l})$, acceptable yields of CNTs are manageable and consistent. Fig. $3 \mathrm{~b}$ is representative of $3 \times$ filtration and shows that whilst unable to meet the extremes of dripcoating, CNT synthesis is far more even throughout. The circumstances of this can be rationalised by considering that full immersion of the $\mathrm{Al}_{2} \mathrm{O}_{3}$ powder takes place as opposed to a selective coating, ensuring all $\mathrm{Al}_{2} \mathrm{O}_{3}$ grits are exposed to the cobalt nitrate solution.
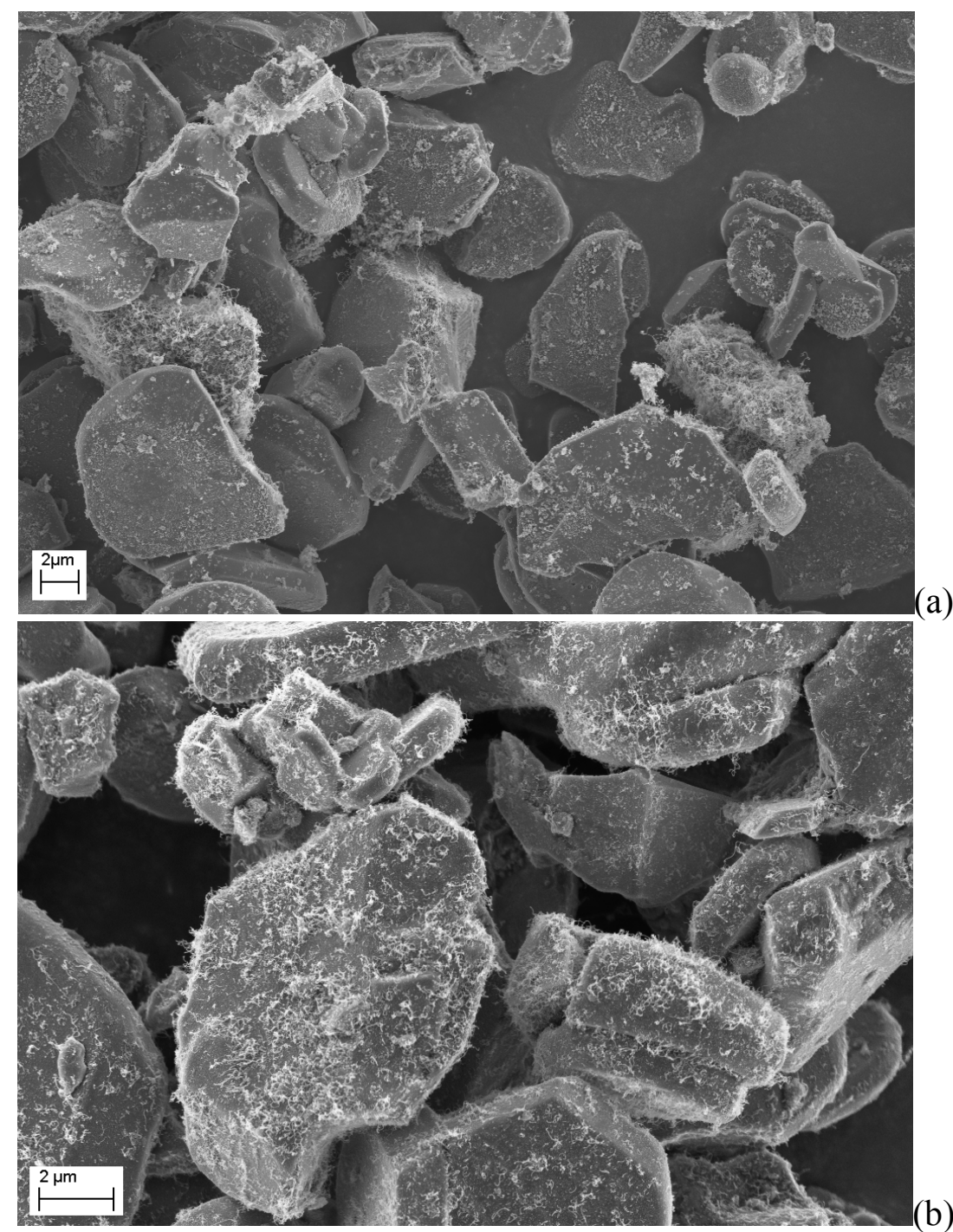

Figure 3: Representative images of CNT growth over an entire sample after CCVD at $650^{\circ} \mathrm{C}$ (a) drip-coating (b) vacuum filtration.

Unfortunately, at this point, we are unable to explain why such a uniform distribution contains a considerable number of perfectly sized catalyst nanoparticles that have failed to grow. Some of the speculations as to the cause include:

- A failed reduction of cobalt (II) nitrate hexahydrate to pure cobalt metal - Electron diffraction spectroscopy (EDS) was undertaken to validate this theory. However, the results 
were contradictory and provided affirmation that the cobalt nitrate precursor had fully reduced into pure cobalt metal.

- The cracking temperature was too low to initiate growth in catalyst nanoparticles which exceed the ideal $20 \mathrm{~nm}$ size $(\sim 30-40 \mathrm{~nm})$ - In order to facilitate the dissolution of carbon into the catalyst particle, either the surface or the entire metal body needs to be in a liquid-state. The critical temperature at which this would usually be achieved is the melting point of the respective metal. For cobalt this would be $1495^{\circ} \mathrm{C}$. However, as described in the experimental procedure, a temperature of only $650^{\circ} \mathrm{C}$ is emitted during CCVD. Carbon diffusion still proceeds because of a nano-size effect which causes both physical and chemical property transformations followed by substantial reductions in the melting temperature. This is known as the Gibbs-Thomson effect and is expressed as:

$$
\Delta T_{m}=\frac{2 T_{m} \gamma}{L \rho r}
$$

where $T_{m}$ is the melting temperature in Kelvin, $\gamma$ is the surface tension, $L$ is the latent heat, $\rho$ is the density and $r$ is the particle radius. By reviewing the equation, it is evident the cobalt catalyst solid-liquid temperature is dictated by the nanoparticle radius with enlargements directly corresponding to a raised melting point. From this it may be deduced that catalyst particles of an increased size need to experience higher temperatures to become active. We attempted CCVD at temperatures of $675-1000^{\circ} \mathrm{C}$ to identify whether synthesis of the previously failed cobalt nanoparticles occurred. Unfortunately, instead of improved growth densities the only changes observed were increased CNT lengths $(\sim 2 \mu \mathrm{m})$, evidenced in Fig. 4. Additionally, at the highest temperatures of $900-1000^{\circ} \mathrm{C}$, the tips of CNTs converge upon one another to create a multiple junctions which form part of an extensive connected network. Further reading on both the aforementioned phenomenon's can be found elsewhere ${ }^{23,31}$.

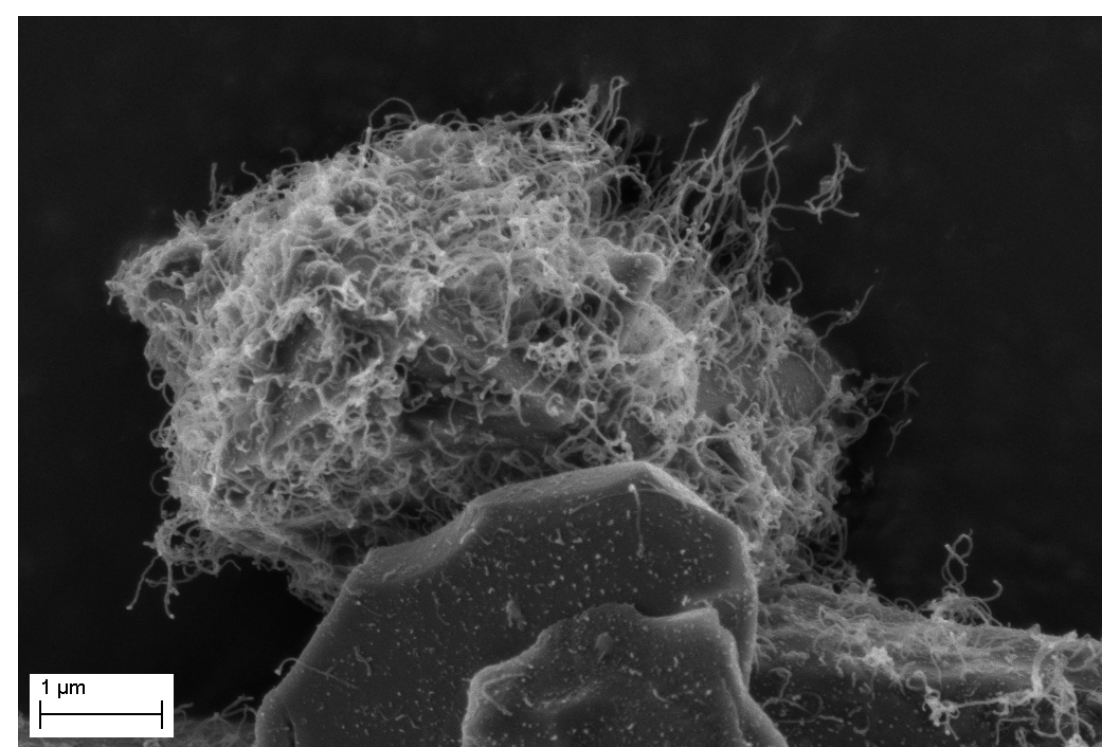

Figure 4: SEM image highlighting the increased CNT lengths produced at higher temperatures, in this case at $800^{\circ} \mathrm{C}$.

- The planar surface morphology promotes strong interactions between the cobalt nanoparticles and the $\mathrm{Al}_{2} \mathrm{O}_{3}$ grits that inhibits the tip-growth mechanism - It has been wellestablished that CNTs are generated via two widely-accepted modes of growth, "tip-growth" and "base-growth" 32 . The circumstance under which either mode is preferential is believed 
to be dependent on the contact angle at the catalyst particle $/ \mathrm{Al}_{2} \mathrm{O}_{3}$ substrate interface. In order to incite tip-growth, a wide contact angle is necessary. This understanding was eventually used to explain the failed growth, as SEM examinations found smooth $\mathrm{Al}_{2} \mathrm{O}_{3}$ particles retaining adequate distributions of cobalt catalyst nanoparticles exhibited the lowest CNT densities. By considering that flatter surfaces provide stronger adhesion, an attrition mill was employed (2hrs at 300RPM) to improve the surface roughness, consequently widening the contact angle. However, the results disagreed with this hypothesis and revealed that ball-milled powder produces less CNTs as it accumulates nano-sized $\mathrm{Al}_{2} \mathrm{O}_{3}$ particles which agglomerate and position themselves on top of the metal catalyst, physically obstructing CNT growth.

(b) Microstructure of the $\mathrm{CNT}-\mathrm{Al}_{2} \mathrm{O}_{3}$ nanocomposites.

Using pure $\mathrm{Al}_{2} \mathrm{O}_{3}$ powder and the $\mathrm{Al}_{2} \mathrm{O}_{3}+\mathrm{CNTs}$ nanocomposite powder produced via vacuum filtration, chemically bonded phosphate ceramics were fabricated. The resultant microstructures are presented in Fig. 5 and Fig. 6. Evaluation of these FEGSEM images reveals a smooth coating of aluminium phosphate $\left(\mathrm{AlPO}_{4}\right)$ over each particle, fusing the structure together, suggesting a successful curing across both compositions.

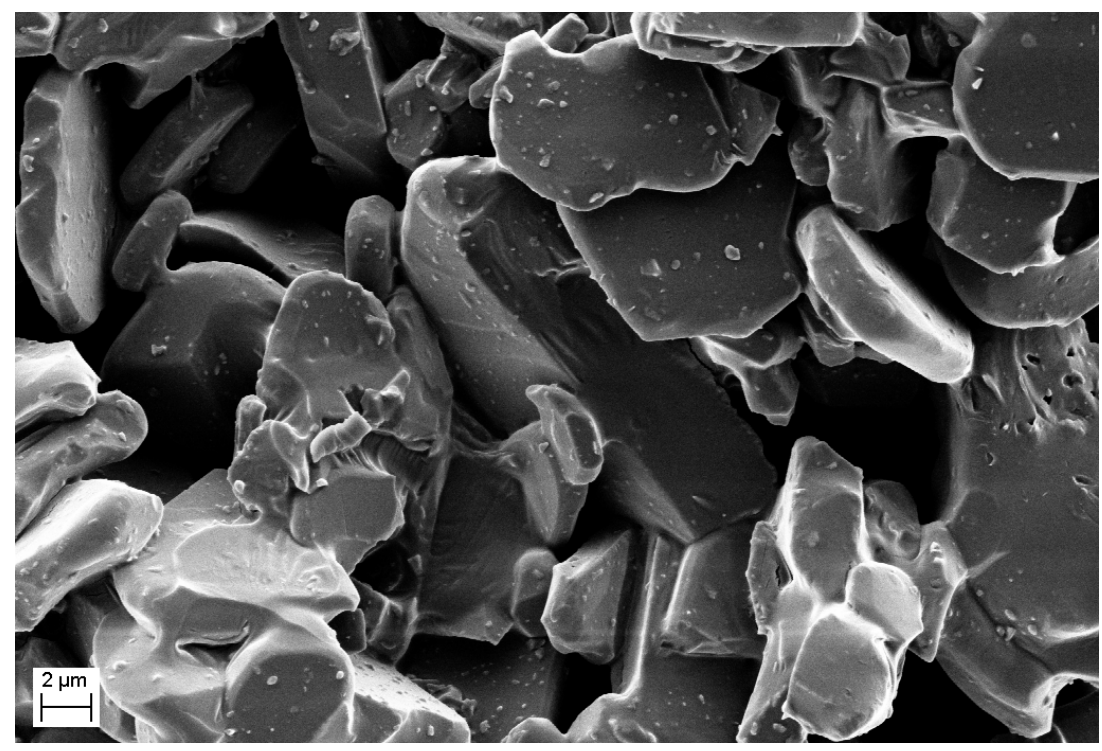

Figure 5: The microstructure of the pure $\mathrm{Al}_{2} \mathrm{O}_{3}$-phosphate ceramic after curing at $150^{\circ} \mathrm{C}$.

However, despite the visual evidence, X-ray diffraction (XRD) results were unable to resolve the peaks commonly associated with an aluminium phosphate phase. This may be due to the very low quantities of $\mathrm{AlPO}_{4}$ within the final ceramics (minimum volume percentage detectable is $\sim 3 \%$ for typical laboratory X-ray powder diffraction), especially considering that the majority of the phosphoric acid is pressed out during die pressing. Fortunately, XRD on identical samples that were allowed to retain larger quantities of the phosphoric acid produced improved data ${ }^{33}$. Fig 7 displays the full $2 \theta$ range measured and specifically shows two relatively weak peaks at $26.4^{\circ}$ and $19.80^{\circ}$ confirming the transformation of $\alpha-\mathrm{Al}_{2} \mathrm{O}_{3}$ into an aluminium phosphate phase. Another notable feature is the broad peak that spans between $19-33^{\circ}$ (magnified in the inset) which seems to indicate the presence of a poor crystallization or amorphous phase ${ }^{34}$, possibly $\mathrm{AlPO}_{4} \cdot \mathrm{H}_{2} \mathrm{O}$.

Although well-bonded, the compaction of the $\mathrm{Al}_{2} \mathrm{O}_{3}$ particles is relatively poor. The majority of this can be attributed to the intentionally low pressures applied during die-pressing, although the large particle size and the potential for shrinkage during the dehydration stage may also be contributing factors. By introducing a vacuum to the pressureless-curing process, porosity may be reduced by assisting in the removal of bubbles which form during dehydration. 


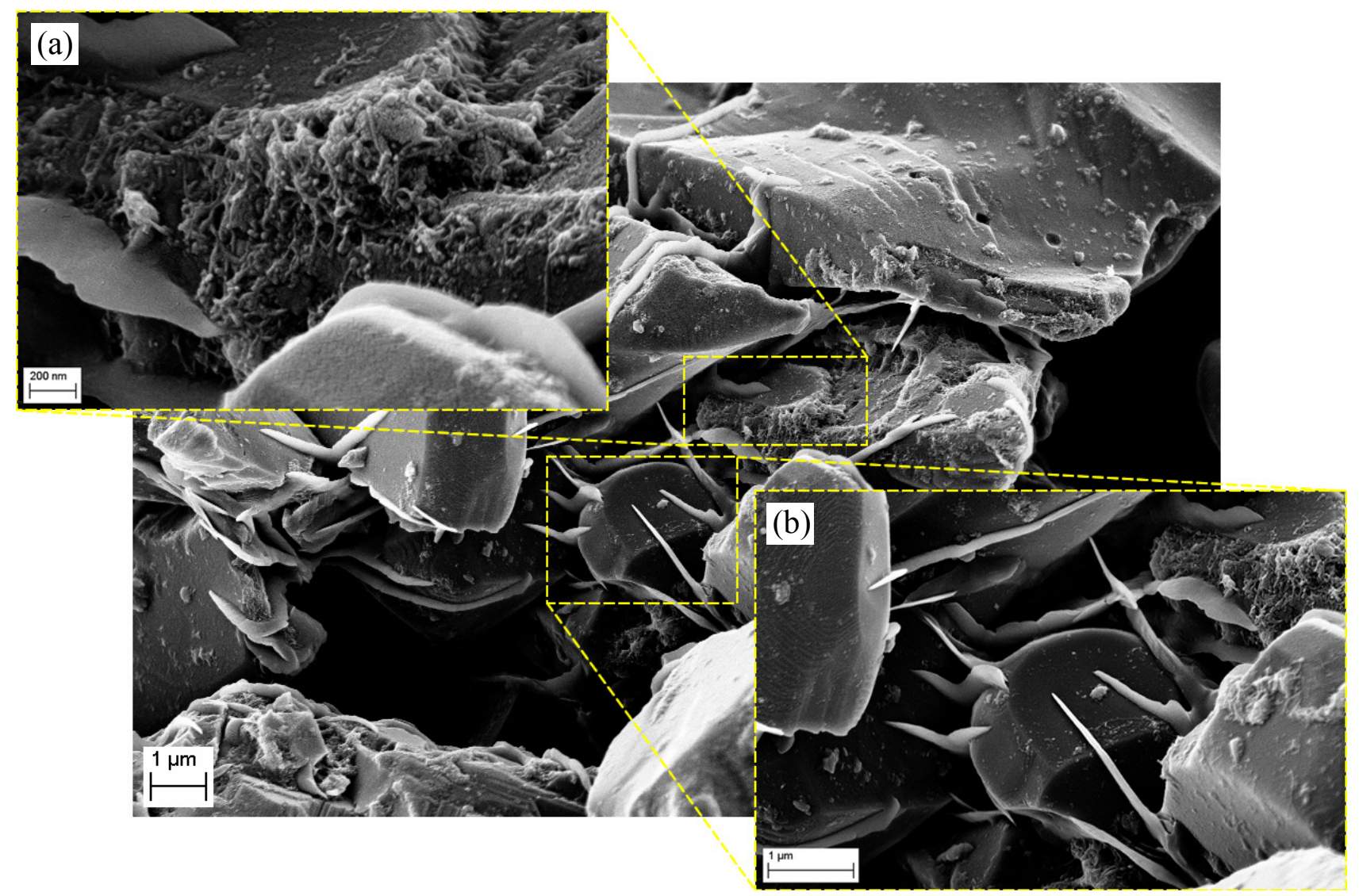

Figure 6: Notable features observed in the microstructure of the CNT reinforced $\mathrm{Al}_{2} \mathrm{O}_{3}$-phosphate ceramic (a) a region of CNT agglomeration (b) the formation of aluminium phosphate "blades".

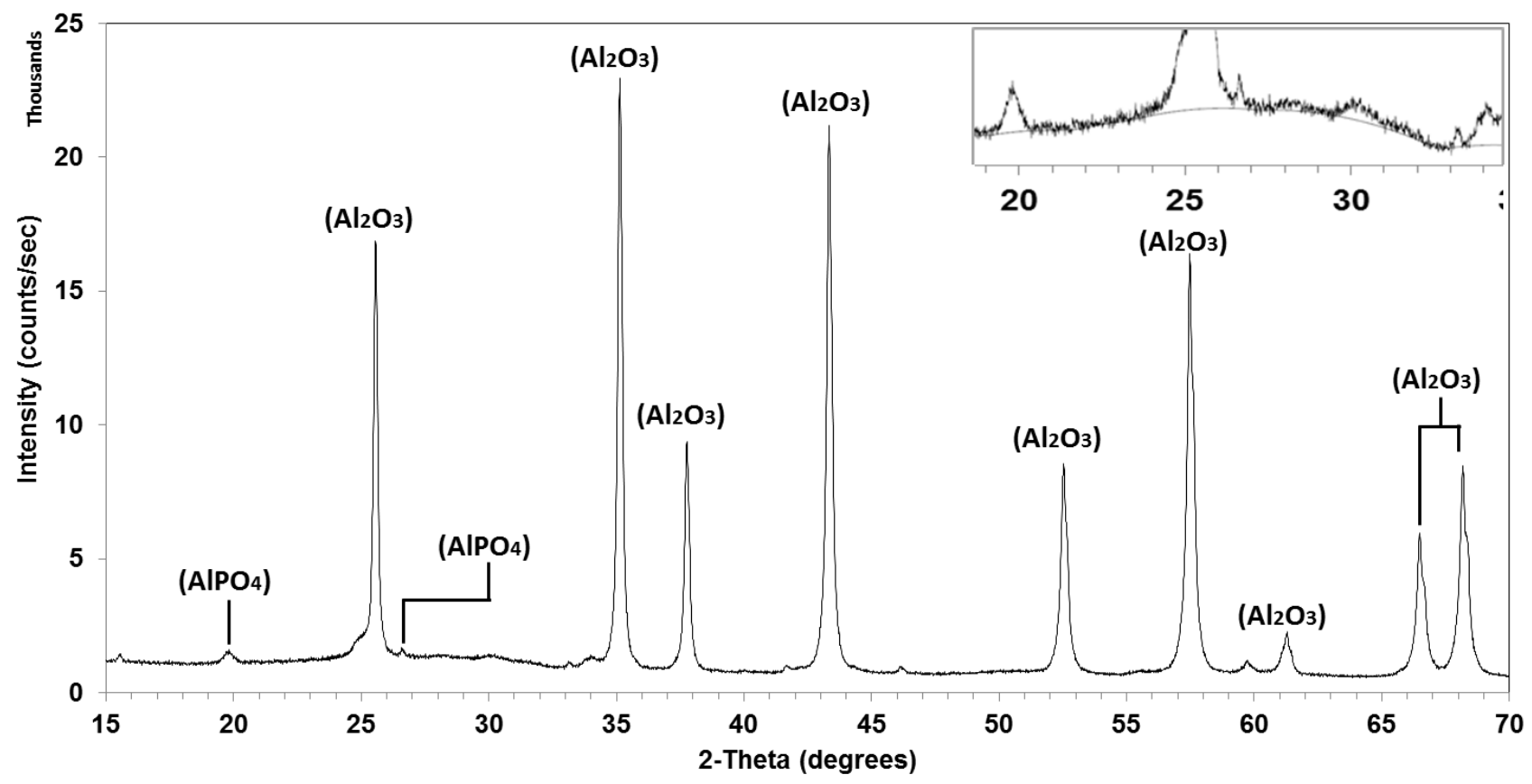

Fig 7. X-ray diffraction pattern for pure aluminium phosphate after dehydration at $130^{\circ} \mathrm{C}$ for $48 \mathrm{hrs}$ and curing at $150^{\circ} \mathrm{C}$ for $48 \mathrm{hrs}$. Note that the starting powder was $\alpha-\mathrm{Al}_{2} \mathrm{O}_{3}$.

Comparing the density measurements of the current samples reveals that the pure $\mathrm{Al}_{2} \mathrm{O}_{3}{ }^{-}$ phosphates ceramics $\left(2.3990 \mathrm{~g} / \mathrm{cm}^{3}\right)$ are marginally denser than the $\mathrm{Al}_{2} \mathrm{O}_{3}-\mathrm{CNTs}$-phosphates $\left(2.2012 \mathrm{~g} / \mathrm{cm}^{3}\right)$ whilst both values are significantly less than the standard density of pure $\alpha-\mathrm{Al}_{2} \mathrm{O}_{3}$ 
$\left(3.99 \mathrm{~g} / \mathrm{cm}^{3}\right)$. However, this is to be expected considering the introduction of a less dense phosphate phase, the low pressures applied during the formation of the green bodies and the cushioning effect of the CNTs which inhibits full densification ${ }^{4}$

Specific features in the $\mathrm{CNT}$ reinforced $\mathrm{Al}_{2} \mathrm{O}_{3}$-phosphate ceramics include extensive agglomeration of the CNTs. It is generally acknowledged that CNTs grown via in-situ CCVD are "anchored" onto the substrate. This has been associated with the amorphous and graphitic carbon build up at the base of the CNTs, adhesion between the catalyst metal and the substrate surface (particularly prevalent during base-growth mechanism) and the physical penetration of CNTs, embedding them into the sub-surface. HRTEM observations (see Fig. 8) show that for the samples presented herein, graphene layers have formed at the interface between the catalyst nanoparticles and the $\mathrm{Al}_{2} \mathrm{O}_{3}$ substrate. This suggests that the CNTs produced via vacuum filtration followed by in-situ CCVD are securely fixed to the $\mathrm{Al}_{2} \mathrm{O}_{3}$ surface. Consequently, it may be deduced that agglomeration originates with the addition of the phosphoric acid. The erosion of the $\mathrm{Al}_{2} \mathrm{O}_{3}$ grits outer surface coincidently damages the graphitic deposits at the base of the CNTs, releasing them from their respective alignment and into a free-state. The aluminium phosphate acts as a liquid medium, facilitating the agglomeration process. Upon dehydration, the volume of this liquid dramatically reduces creating clumps of CNTs at random sites, as illustrated in Fig. 6a. More recent work has managed to reduce the occurrence of CNT agglomeration by adding smaller pure $\mathrm{Al}_{2} \mathrm{O}_{3}$ grains to the $\mathrm{Al}_{2} \mathrm{O}_{3}+\mathrm{CNT}$ powder prior to phosphoric acid impregnation. These finer particles sacrificially dissolve to form the aluminium phosphate gel leaving the larger CNT covered particles unperturbed.

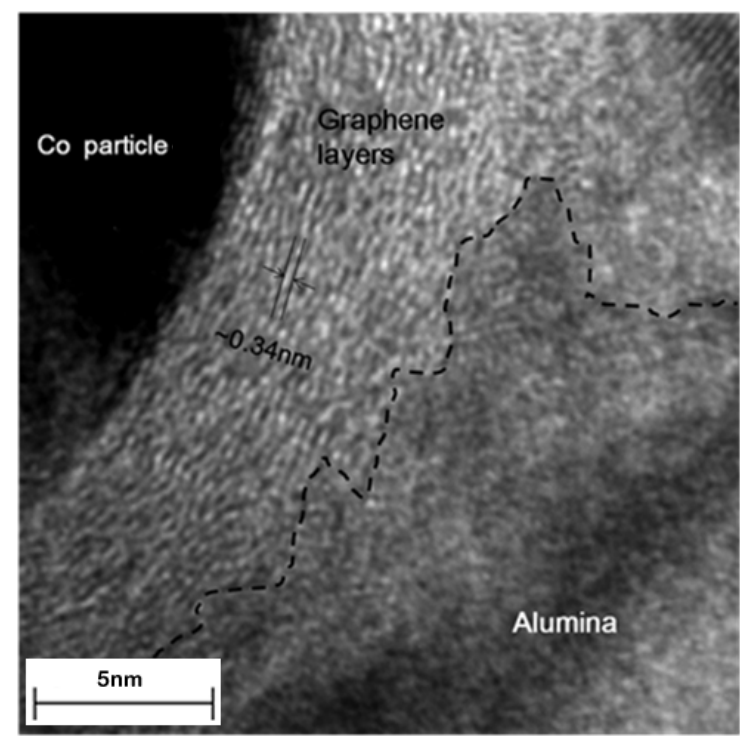

Fig 8. HRTEM lattice measurements at the interface between the $\mathrm{Al}_{2} \mathrm{O}_{3}$ substrate and a selected CNT.

In other regions, the aluminium phosphate contains individual CNTs that run parallel with the morphology of the $\mathrm{Al}_{2} \mathrm{O}_{3}$ particle. We speculate that these CNTs have remained coupled with the $\mathrm{Al}_{2} \mathrm{O}_{3}$ surface and have been overwhelmed by the aluminium phosphate mixture causing them to topple. Dehydration and curing has subsequently encased the CNTs in position.

The most notable addition seen in the $\mathrm{Al}_{2} \mathrm{O}_{3}$-CNTs-phosphate ceramics is the development of a new phase. Demonstrated in Fig. 6b, this presents itself as long "blades" of crystalized aluminium phosphate that span across multiple particles. The manner in which this phase emerges is still inconclusive. However, further SEM imagery suggests that gradual and continuous layers of aluminium phosphate sequentially glaze and harden over particular CNTs slowly evolving into the distinctive "blade" form. At present, the mechanical characteristics of these "blades" and the property improvement on the entire $\mathrm{Al}_{2} \mathrm{O}_{3}$-phosphate ceramic remain unknown. 


\section{CONCLUSION}

After two differing modes of catalyst distribution, in-situ CNTs were successfully grown on $\mathrm{Al}_{2} \mathrm{O}_{3}$ substrate particles via CCVD. The resultant $\mathrm{Al}_{2} \mathrm{O}_{3}+\mathrm{CNT}$ powders were subsequently densified by impregnating phosphoric acid to form CNT reinforced $\mathrm{Al}_{2} \mathrm{O}_{3}$-phosphates ceramics. Observational analysis under SEM of these ceramic nanocomposites highlight a number of distinctive features caused by the addition of CNTs to the ceramic matrix. The most notable of these include sites of agglomerated CNTs and the formation of crystalized aluminium phosphate "blades". In addition, density measurements revealed that the CNT reinforced $\mathrm{Al}_{2} \mathrm{O}_{3}$-phosphate ceramics were, by comparison, marginally less dense than monolithic $\mathrm{Al}_{2} \mathrm{O}_{3}$-phosphate ceramics.

\section{REFERENCES}

1 Mcyyappan, M. Nanotechnology in aerospace applications. Nanotechnology Aerospace Applications. [Online] 2006, pp. 1-2. Available from: http://ftp.rta.nato.int/public//PubFullText/RTO/EN/RTO-EN-AVT-129///EN-AVT-129-06.pdf

[Accessed ${ }^{\text {th }}$ September 2012]

${ }^{2}$ Baughman, R. H., Zakhidov, A. A. \& de Heer, W. A. Carbon nanotubes-the route toward applications. Science. 2002, 297 (5582), pp. 787-792.

${ }^{3}$ Makar, J. M. \& Beaudoin, J. J. Carbon nanotubes and their application in the construction industry. In: Bartos, P. J. M., Hughes, J. J., Trtik, P. \& Zhu, W. (Ed) 1st International Symposium on Nanotechnology in Construction. Royal Society of Chemistry, Paisley, Scotland, 2003, pp. 331341

${ }^{4}$ Van Lier, G., Alsenoy, C., Van Doren, V. \& Geerling, P. Ab initio study of the elastic properties of single-walled carbon nanotubes and grapheme. Chemical Physics Letter. 2000, 326, pp. 181-185.

${ }^{5}$ Treacy, M. M. J., Ebbesen, T. W., Gibson, J. M. Exceptionally high Young's modulus observed for individual carbon nanotubes. Nature. 1996, 381, pp. 678-680.

${ }^{6}$ Yu, M. F., Lourie, O., Dyer, M. J., Moloni, K., Kelly, T. F. \& Ruoff, R. S. Strength and breaking mechanism of multiwalled carbon nanotubes under tensile load. Science. 2000, 287, pp. 637-640.

${ }^{7}$ Ando, Y., Zhaoa, X., Shimoyama, H., Sakai, G. \& Kaneto, K. Physical properties of multiwalled carbon nanotubes. International Journal of Inorganic Materials. 1999, 1, pp. 77-82.

${ }^{8}$ Thess, A., Lee, R., Nikolaev, P., Dai, H., Petit, P., Robert, J., Xu, C., Hee Lee, Y., Gon Kim, S., Rinzler, A. G., Colbert, D. T., Scuseria, G. E., Tománek, D., Fischer, J. E. \& Smalley, R. E. Crystalline ropes of metallic carbon nanotubes. Science. 1996, 273, pp. 483-487.

9 Baughman, R. H., Zakhidov, A. A. \& de Heer, W. A. Carbon nanotube-the route toward applications. Science. 2000, 297, pp. 787-792.

${ }_{10}$ Biercuk, M. J., Llaguno, M. C., Radosavlijevic, M., Hyun, J. K. \& Johnson, A. T., Carbon nanotube composites for thermal management. Applied Physics Letter. 2002, 80, pp. 2767-2769.

${ }^{11} \mathrm{Ma}, \mathrm{R} . \mathrm{Z}$., Wu, J., Wei, B. Q., Liang, J \& Wu, D. H. Processing and properties of carbon nanotubes-nano SiC ceramics. Journal of Material Science. 1998, 33, pp. 5243-5246.

12 Zhang, H. L., Lia, J. F., Yao, K. F. \& Chen, L. D. Spark plasma sintering and thermal conductivity of carbon nanotube bulk materials. Journal of Applied Physics. 2005, 97, pp. $114310-$ 114315.

${ }^{13}$ Liu, Y., Bian, G., Miller, T. \& Chiang, T. Visualising electronic chirality and berry phases in graphene systems using photoemission with circularly polarized light. Physical Review Letters. 2011, 107 (16), pp. 1-5.

${ }^{14}$ Novoselov, K. S., Morozov, S. V., Mohinddin, T. M. G., Ponomarenko, L. A., Elias, D. C., Yang, R., Barbolina, I. I., Blake, P., Booth T. J., Jiang, D., Giesbers, J., Hill, E. W. \& Geim, A. K. Electronic properties of graphene. Physica Status Solidi (b). 2007, 224 (11), pp. 4106-4111.

${ }^{15}$ Park, S. \& Ruoff, R. Chemical methods for the production of graphenes. Nature nanotechnology. 2009, 4, pp. 217-224. 
${ }^{16}$ Chen, J., Jang, C., Xiao, S., Ishigami, M. \& Fuhrer, M. Intrinsic and extrinsic performance limits of graphene devices on $\mathrm{SiO}_{2}$. Nature Nanotechnology. 2008, 3 (4), pp. 206-209.

17 Charlier, J. C., Eklund, P. C., Zhu, J. \& Ferrari, A. C. Electron and phonon properties of graphene: Their relationship with carbon nanotubes. In: Jorio, A., Dresselhaus, G. and Dresselhaus, M.S. (Ed) Carbon nanotubes: Advanced topics in the synthesis, structure, properties and applications. Springer-Verlag, New York, USA, 2008, pp. 673-709.

${ }^{18}$ Journet, C. \& Bernier, P. Production of carbon nanotubes. Applied Physics (A). 1998, 67, pp. 1-9.

19 Vaisman, L., Wagner, H. D. \& Marom, G. The role of surfactants in dispersion of carbon nanotubes. Advances in Colloid and Interface Science. 2006, 128-130, pp. 37-46.

${ }^{20}$ Zhang, W., He, W. \& Jing, X. Preparation of a stable graphene dispersion with high concentration by ultrasound. Journal of Physical Chemistry (b). 2010, 114 (32), pp. 10368-10373.

${ }^{21}$ Park, S., An, J., Jung, I., Piner, R. D., An, S. J., Li, X., Velamakanni, A. \& Ruoff, R. S. Colloidal suspensions of highly reduced graphene oxide in a wide variety of organic solvents. Nano Letters. 2009, 9 (4), pp. 1593-1597.

${ }^{22}$ Flahaut, E., Laurent, C. \& Peigney, A. Catalystic CVD synthesis of double and triple-walled carbon nanotubes by the control of the catalyst preparation. Carbon. 2005, 43 (2), pp. 375-383.

${ }^{23}$ Peigney, A., Flahaut, E., Laurent, C., Chastel, F. \& Rousset, A. Aligned carbon nanotubes in ceramic-matrix nanocomposites prepared by high-temperature extrusion. Chemical Physical Letters. 2002, 352 (1-2), pp. 20-25.

${ }^{24}$ Balani, K., Zhang, T. Karakoti, A., Li, W. Z., Seal, S. \& Agarwal, A. In-situ carbon nanotube reinforcements in a plasma-sprayed aluminum oxide nanocomposite coating. Acta Materialia. 2008, 56 (3), pp. 571-579.

${ }^{25}$ Jin, F., Liu, Y., Day, C. \& Little, S. Degradation of vertically aligned carbon nanotubes at growth interface joints at high temperatures and its impact on electron emission properties. $M R S$ Proceedings. 2008, 1137.

${ }^{26}$ Reich, S., Thomsen, C. \& Maultzsch, J. Carbon nanotubes, $2^{\text {nd }}$ edition. Wiley-VCH, Berlin, 2005, pp. 1-4.

${ }^{27}$ Lan, Y., Wang, Y. \& Ren, Z. F. Physics and applications of aligned carbon nanotubes. Advances in Physics. 2011, 60 (4), pp. 553-678.

${ }^{28}$ Kiang, C. Electron irradiation induced dimensional change in bismuth filled carbon nanotubes. Carbon. 2000, 38, pp.1699-1701.

${ }^{29}$ Ma, J., Wang, J. N. \& Wang, X. X. Large-diameter and water-dispersible single-walled carbon nanotubes: synthesis, characterisation and applications. Journal of Material Chemistry. 2009, 19, pp. 3033-3041.

${ }^{30}$ Konno, T. J. \& Sinclair, R. Crystallization of amorphous carbon in carbon-cobalt layered thin films. Acta Metallurgica et Materialia. 1995, 42, pp. 471-484.

${ }^{31}$ Kumar, M. \& Ando, Y. Controlling the diameter distribution of carbon nanotubes grown from camphor on a zeolite support. Carbon, 2005, 43, pp. 533-540.

${ }^{32}$ Baker, R. T. K. \& Waite, R. J. Formation of carbonaceous deposits from the platinum-iron catalyzed decomposition of acetylene. Journal of Catalysis. 1975, 37 (1), pp. 101-105.

${ }^{33}$ Arthur, S. Development of coatings for improving friction performance of carbon fibre ceramic composites. unpublished doctoral thesis, Loughborough University.

${ }^{34}$ Boonchom, B. \& Kongtaweelert, S. Study of kinetics and thermodynamics of the dehydration reaction of $\mathrm{AlPO}_{4} \cdot \mathrm{H}_{2} \mathrm{O}$. Journal of Thermal Analysis and Calorimetry. 2010, 99 (2), pp. 531-538. 